\title{
GPPS-BJ-2019-0020
}

\section{Influence of Mainstream Flow Oscillations on Spatio-Temporal Variation of Leading-Edge Film Cooling Effectiveness}

\author{
Hongyi Shao, Wenwu Zhou*, Yingzheng Liu, Di Peng \\ School of Mechanical Engineering, Shanghai Jiao Tong University \\ 800 Dongchuan Road, 200240 Shanghai, China. \\ *Zhouww@sjtu.edu.cn
}

\begin{abstract}
The influence of mainstream flow oscillations on spatiotemporal variation of leading-edge film cooling effectiveness is investigated in this study using fast-response pressure sensitive paint (fast-PSP) technique. Oscillations with different amplitudes and frequency in mainstream flow are generated by periodic blockage using different pairs of counter-rotating lobes driven by stepper motors. The leadingedge model has semi-circular shape with diameter of $30 \mathrm{~mm}$.
\end{abstract}

\section{INTRODUCTION}

Turbine Entry Temperature (TET) has a significant influence on gas turbines' performance and thermal efficiency. The higher TET is, higher efficiency gas turbines will be able achieve. Nowadays the TET has risen far above the material capability of the single crystal cast alloys. [4] Film cooling, as an essential measure to protect the turbine components against the harsh high temperature environment, is of extreme importance for gas turbines' performance. By introducing coolant from compressor bleeding, film cooling aims to protect the surface from the cooling holes to downstream of the holes. Nowadays it has be widely used in gas turbine components and has significantly

The leading edges of the first stage HPT vanes will endure the highest temperature in the hot section. Most former studies focus on the film cooling efficiency under steady mainstream flow; However, due to combustion instability and rotor-stator interaction, the flow in the turbine is naturally unstable. Only a few studies have studied the relationship between mainstream oscillation and film cooling efficiency. Ligrani et al. [5-6] investigated relations between coolant flow structure and bulk flow pulsations. Recently Baek et al. [1] studied influence of oscillations in mainstream on film cooling at different blowing ratios using ANSYS Fluent, Zhou et al. [7] experimentally studied flat plate film cooling under mainstream oscillations. Therefore, it is of great significance to study the interaction between the oscillating mainstream flow and the spatio-temporal variation of cooling effectiveness on the leading edge.

We performed a study to investigate the influence of mainstream flow oscillations on leading-edge film cooling effectiveness. Using fast-response pressure sensitive paint (fast-PSP) technique, frequency was varied in the mainstream flow in order for us to study both the instantaneous film cooling effectiveness but also the phase-averaged effectiveness.

\section{METHODOLOGY}

\section{Experimental Setup and Test Model}

The experiment is conducted on a low-speed, open-circuit wind tunnel with a transparent test section in School of Mechanical Engineering, Shanghai Jiao Tong University. The wind tunnel is driven by a downstream blower. Honeycombs and meshes are placed in front of the test section in order to supply a low-turbulence mainstream flow. The turbulence intensity $(T u)$ is found to be around $1.7 \%$ by using hotwire anemometer. The cross section of the test section is $150 \mathrm{~mm}$ (width)*100mm (height).

Table 1. Mainstream Average Conditions

\begin{tabular}{|l|l|}
\hline Mainstream Average Flow Speed $(\mathrm{U})$ & $15 \mathrm{~m} / \mathrm{s}$ \\
\hline Turbulence Intensity without Oscillation $(\mathrm{Tu})$ & $1.7 \%$ \\
\hline Reynolds Number for Leading Edge $\left(\mathrm{Re}_{\mathrm{D}}\right)$ & 30000 \\
\hline
\end{tabular}




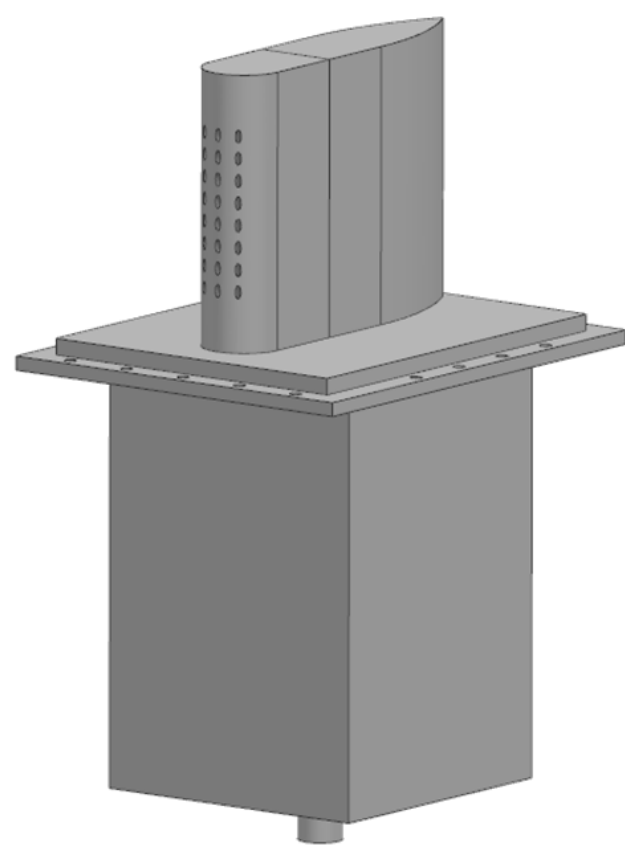

Figure 1 Overall View of the Test Model

The test part, as shown in figure 1, is made of UV curable resin by rapid prototype machine. Figure 2 shows the leadingedge model applied in this study, which has three rows of film cooling holes at the leading-edge. The detailed geometry dimensions are shown in table 1 below.

Table 2. Detailed Dimensions of the Test Part

\begin{tabular}{|l|l|}
\hline Cooling Hole Diameter (d) & $2 \mathrm{~mm}$ \\
\hline Cooling Hole Pitch (p) & $8 \mathrm{~mm}(4 \mathrm{~d})$ \\
\hline Cooling Hole Length (L) & $9.46 \mathrm{~mm}(4.73 \mathrm{~d})$ \\
\hline Cooling Hole Row Number & 3 \\
\hline Cooling Hole Numbers in Each Row & 8 \\
\hline Cooling Hole Position & $0^{\circ}, \pm 30^{\circ}$ \\
\hline Streamwise Angle & $90^{\circ}$ \\
\hline Spanwise Angle & $25^{\circ}$ \\
\hline Leading Edge Diameter (D) & $30 \mathrm{~mm}(15 \mathrm{~d})$ \\
\hline Leading Edge Height (H) & $100 \mathrm{~mm}$ \\
\hline
\end{tabular}

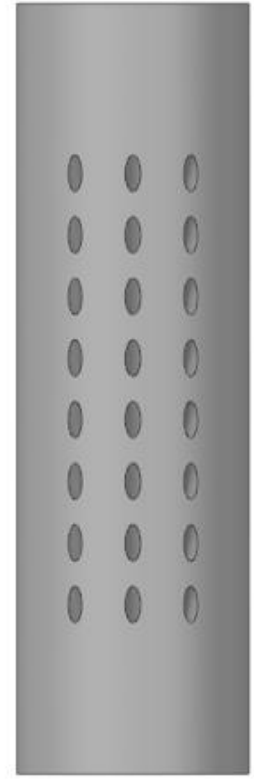

\section{Figure 2 Frontal View of Leading-Edge Model}

The leading-edge model is semi-circular with $30 \mathrm{~mm}$ diameter and $100 \mathrm{~mm}$ in height. This will introduce $20 \%$ blockage in the test section. The test model has $25^{\circ}$ inclined circular holes with a diameter $(d)$ of $2 \mathrm{~mm}$, and there are 8 holes in each row of cooling holes, as shown in figure 3 . The pitch of the holes is $8 \mathrm{~mm}(P=4 d)$. Overall length of the hole is $9.46 \mathrm{~mm}(L=4.73 d)$ The test part is mounted on a plenum $(100 \mathrm{~mm} * 100 \mathrm{~mm} * 150 \mathrm{~mm})$. The surface of the test model is carefully polished by fine sandpaper. Airtightness is ensured by applying Vaseline between gaps of the models.

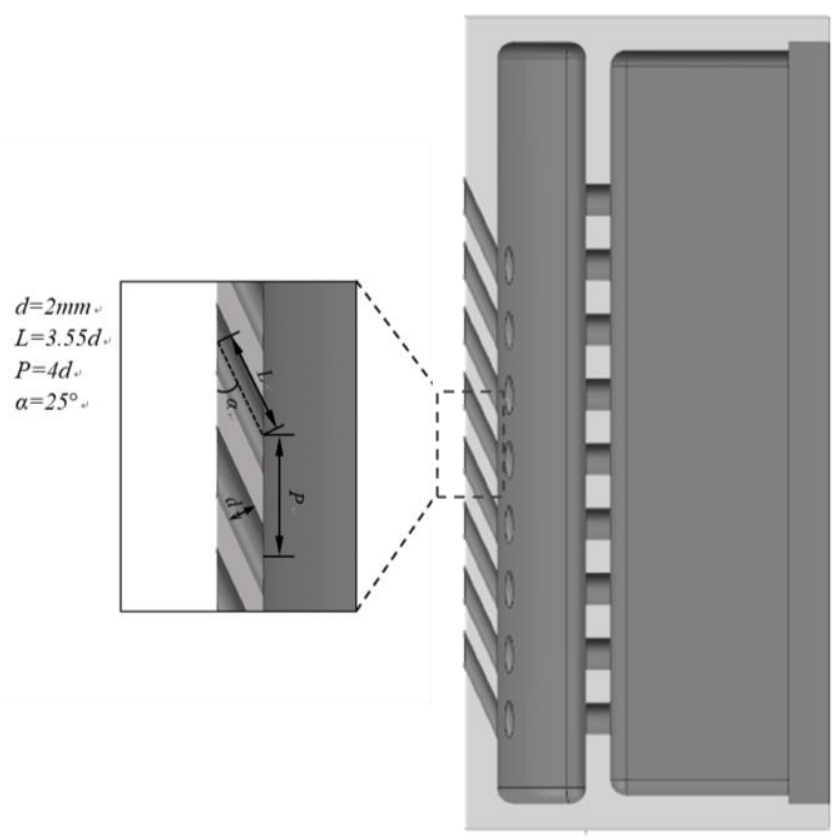

Figure 3 Cross Section of the Leading Edge Model 
Coolant flow $\left(\mathrm{CO}_{2}\right)$ is provided from a pressurized $\mathrm{CO}_{2}$ gas cylinder with density ratio $\left(D R=\rho_{c} / \rho_{\infty}\right)$ of 1.53 . The coolant gas goes through a heat exchanger, which is long copper tube submerged in constant temperature water to reach the same temperature with mainstream temperature before the coolant reaches the plenum. A flowmeter is then positioned in the gas path to determine the volumetric flow rate in order to realize the designated blowing ratio for this study. The blowing ratio $\left(M=\rho_{c} U_{c} / \rho_{\infty} U_{\infty}\right)$ is chosen at $0.5,1.0$ and 1.5 .

\section{Table 3. Coolant Conditions}

\begin{tabular}{|l|l|}
\hline Coolant Type & $\mathrm{CO}_{2}$ \\
\hline Coolant Density Ratio (DR) & 1.53 \\
\hline Coolant Blowing Ratio (M) & $0.5,1.0,1.5$ \\
\hline
\end{tabular}

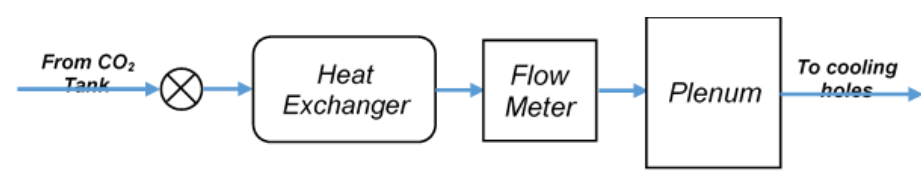

Figure 5 Schematic of Coolant Gas Path

\section{Measurement Technique}

In this study, the fast PSP technique is used to determine the adiabatic film cooling effectiveness, which is defined as:

$$
\eta=\frac{T_{\infty}-T_{a w}}{T_{\infty}-T_{c}}
$$

The adiabatic film cooling effectiveness is a nondimensional number which determines the efficiency how the coolant protects the surface. The higher $\eta$ is, the better local surface is protected by the coolant. The PSP technique uses mass transfer analogy to picture heat transfer on the surface due to the similarity of the control equations. In this way, not only can we reduce the cost and difficulty of the experiment, but also eliminate the errors caused by heat conduction and radiation. Details of this technology can be founded in previously published articles. [2-3, 7]

A Fast-Response polymer-ceramic PSP (PtTFPP as luminophore) is applied on the test model. The in-house prepared paint showed up to $6 \mathrm{kHz}$ dynamic response in the resonance tube calibration. During the experiment, a highpower ultraviolet LED light (wavelength $385 \mathrm{~mm}$ ) was positioned as the side of the test section as an excitation source for the PSP. When excited by the UV light, the luminescent molecules will emit light which intensity is related with local oxygen concentration. The quantitative relationship of this 'oxygen quenching' effect is determined by calibration in our lab. By supplying coolant gas $\left(\mathrm{CO}_{2}\right.$ in this experiment), the oxygen concentration changes in a way analogous to the heat transfer process, leaving a pattern with different luminescent intensity indicating adiabatic film cooling effectiveness. A high-speed camera was used to record the photoluminescence. Sampling rate for the camera was $4000 \mathrm{~Hz}$

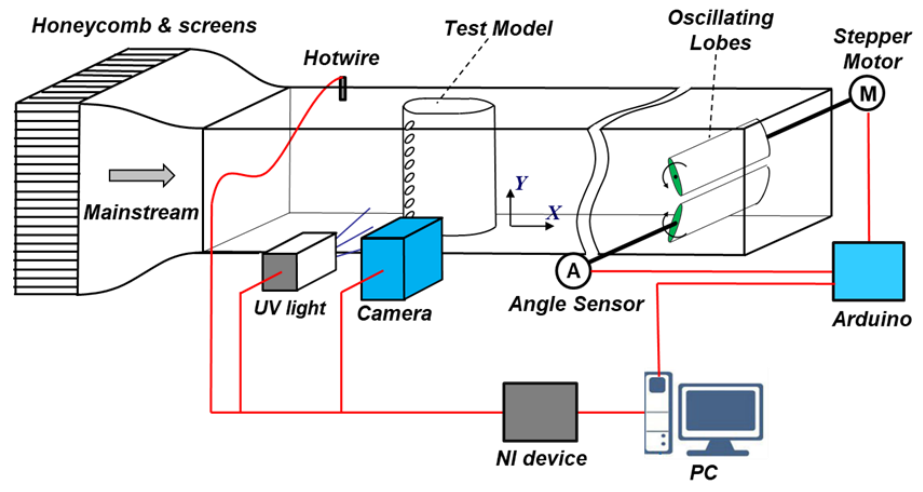

Figure 4 Schematic of the Experiment Layout

Two counter-rotating lobes of the same size placed downstream of the test section are used to generate oscillations in mainstream flow. The lobes are fixed on a gearbox, driven by a stepper motor. The gearbox guarantees the two lobes have the exact opposite angular velocity and phase angle. The designated oscillation frequency, which can be continuously adjusted from 0 to $50 \mathrm{~Hz}$, is achieved by controlling the rotational speed of the driving stepper motor by Micro Control Unit (MCU, Arduino Uno). A total of 5 pairs of lobes are 3-D printed. They share the same length of $150 \mathrm{~mm}$ and thickness of $7 \mathrm{~mm}$, but its width varies from $20 \mathrm{~mm}$ to $40 \mathrm{~mm}(20 \mathrm{~mm}$, $25 \mathrm{~mm}, 30 \mathrm{~mm}, 35 \mathrm{~mm}, 40 \mathrm{~mm}$ ), which can provide from $40 \%$ to $80 \%$ maximum blockage for the mainstream flow. The phase angle of the blockage is continuously measured by a hall-effect angle sensor and sent to MCU as a feedback. Oscillation patterns in mainstream velocity as a dynamic response of sinusoidal mainstream blockage was measured by a hot-wire probe (Dantec 55P11-16) and plotted into Bode diagrams for each pair of lobes. Then the appropriate lobe type-frequency conditions are picked to set test conditions with same oscillation amplitude but with different frequencies. The phase delay of velocity relative to the blockage is recorded to provide information in order to predict the phase of the velocity oscillation from the phase of the blockage. In present study, we apply the "phase lock" conditions. Every time the mainstream comes to a predesignated phase, the pulsed trigger signal will be given by the MCU to the camera. The final frequency is determined at $7 \mathrm{~Hz}$ and $25 \mathrm{~Hz}$ so that approximately same oscillation amplitude is achieved and the velocity waveform behaves sinusoidal.

Table 4. Oscillation Conditions

\begin{tabular}{|c|c|c|c|c|}
\hline$f(\mathrm{~Hz})$ & $A(\%)$ & $U_{\infty}(\mathrm{m} / \mathrm{s})$ & $M$ & $S t_{c}$ \\
\hline \multirow{3}{*}{0} & \multirow{3}{*}{0} & \multirow{3}{*}{15} & 0.5 & 0 \\
\hline & & & 1.0 & 0 \\
\hline & & & 1.5 & 0 \\
\hline \multirow{3}{*}{7} & \multirow{3}{*}{10.2} & \multirow{3}{*}{15.3} & 0.5 & 0.816 \\
\hline & & & 1.0 & 0.408 \\
\hline & & & 1.5 & 0.273 \\
\hline \multirow{3}{*}{25} & \multirow{3}{*}{11.3.} & \multirow{3}{*}{15.8} & 0.5 & 2.823 \\
\hline & & & 1.0 & 1.4117 \\
\hline & & & 1.5 & 0.941 \\
\hline
\end{tabular}




\section{RESULTS AND DISCUSSION}

\subsection{Calibration}

Since the LE is a cylindrical surface, the filmed pictures inevitably have some distortion. A checkerboard pattern is applied on the measuring surface of the leading edge. Every checkerboard square is $1 \mathrm{~mm}$ in width and height, and the camera is at the exact location where it will film the film cooling effectiveness. By applying proper homography transformation using the identified corner points, the distorted picture is mapped back to a $2 \mathrm{D}$ flat surface. In the newly calibrated picture, $1 \mathrm{~mm}$ corresponds with 24 pixels in length.

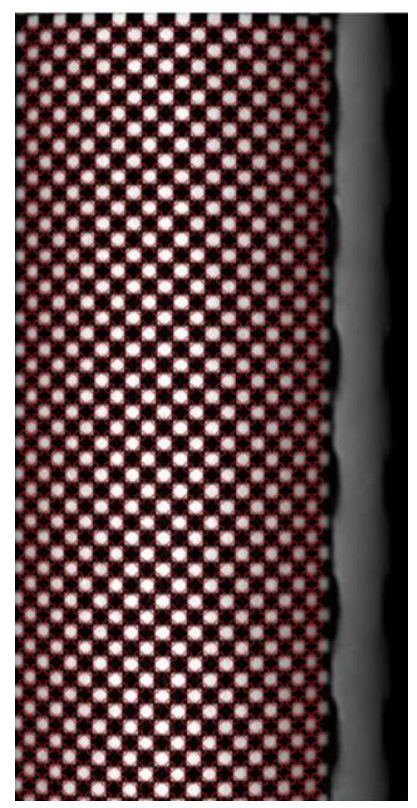

(a) Before Calibration (Corner Points Identified)

Figure 5. Image calibration for cylindrical surface

3.2 Adiabatic Film cooling efficiency at steady mainstream flow

The time-averaged result under steady mainstream flow is shown in Figure 6.

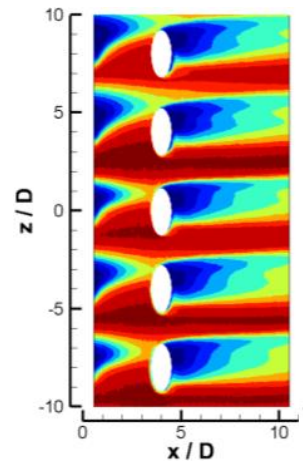

(a)

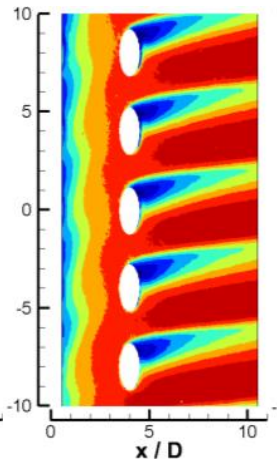

(b)

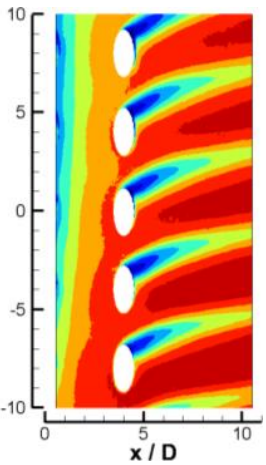

(c) (a) $M=0.5$, (b) $M=1.0$, (c) $M=1.5$

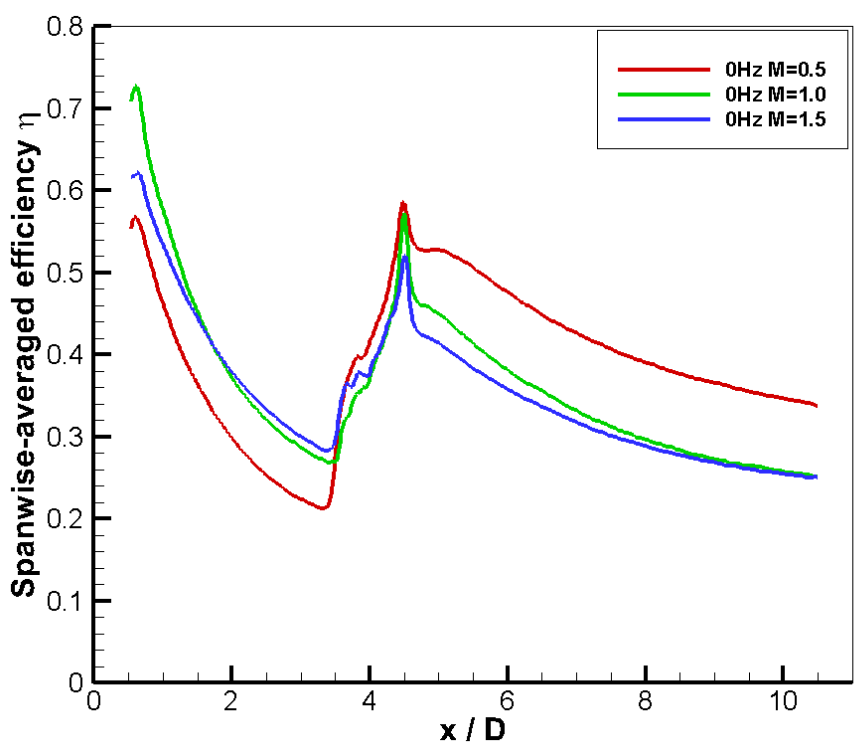

Figure 7. The spanwise-averaged, time-averaged result at different blowing ratio

As shown in Figure 7, when there's no oscillation in mainstream flow, $M=1.0$ provides higher efficiency between first and second row of holes, while the $M=0.5$ case provides better efficiency after the second row of holes due to better coverage of coolant film, which is shown in Figure 6. This could be caused by the jet lift-off at higher blowing ratio.

\subsection{Time-averaged adiabatic film cooling efficiency}

Time-averaged film cooling efficiency is calculated to investigate the overall influence of mainstream oscillation by averaging the local film cooling effectiveness over time:

$$
\bar{\eta}=\frac{1}{t_{1}} \int_{0}^{t_{1}} \eta(x, z, t) d t
$$

Among Equation (2) $t_{1}$ is the sampling time when acquiring local film cooling effectiveness.

The averaged adiabatic film cooling efficiency is first investigated to study the influence of mainstream oscillation on film cooling effectiveness distribution. Three different blowing ratios of $\mathrm{M}=0.5,1.0,1.5$ are adapted. The mainstream oscillation frequency is chosen at $0 \mathrm{~Hz}$ (baseline condition), $7 \mathrm{~Hz}$ and $25 \mathrm{~Hz}$. The area of interest is selected as $0.5<\mathrm{x} / \mathrm{D}<10.5$ and $-10<\mathrm{z} / \mathrm{D}<10$. When calculating the spanwise-averaged effectiveness, the averaging range is selected from $-6<\mathrm{z} / \mathrm{D}<6$.

\subsubsection{Time-averaged effectiveness, $M=0.5$}




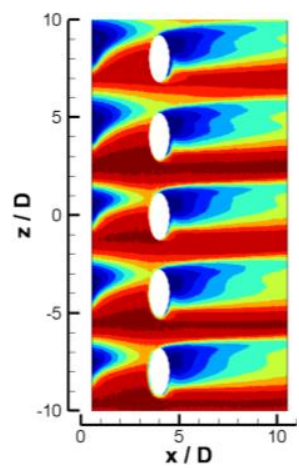

(a)

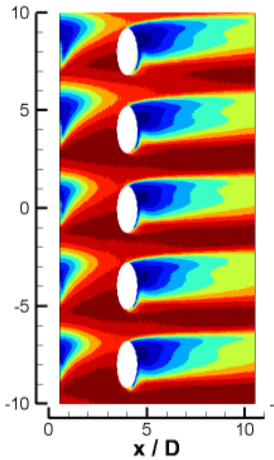

(b)

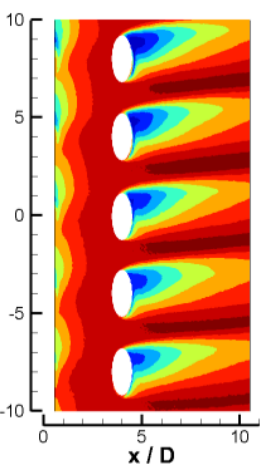

(c)

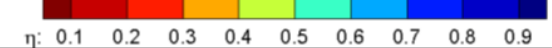

Figure 8. Time-averaged result at $\mathbf{M}=\mathbf{0 . 5}$

(a) $f=0 H z$, (b) $f=7 \mathrm{~Hz}$, (c) $f=25 \mathrm{~Hz}$

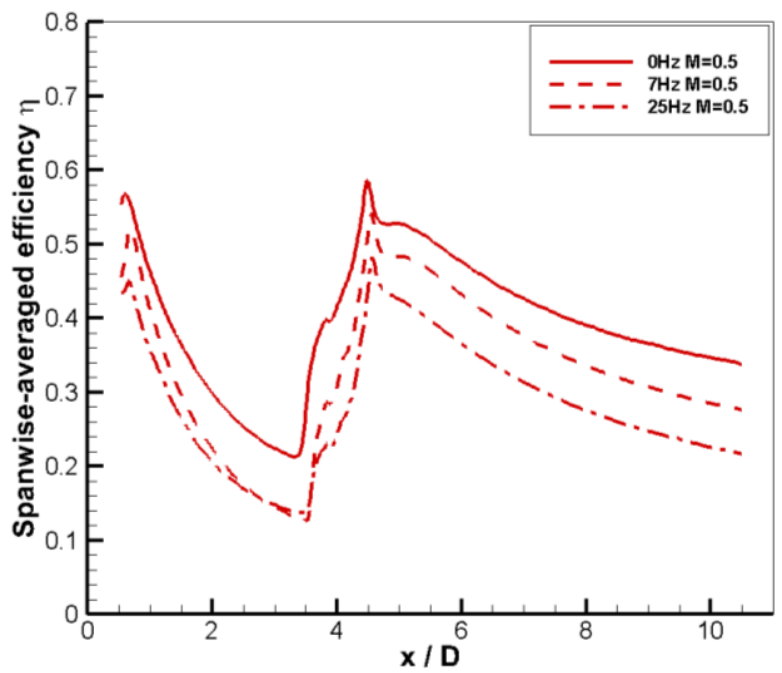

Figure 9. Spanwise \& time-averaged effectiveness profile at $\mathbf{M}=0.5$

With blowing ratio is anchored at $\mathrm{M}=0.5$, Figure 8 compares the time averaged result of film cooling effectiveness distribution under different frequencies, and Figure 9 pictures the spanwise \& time averaged result. A significant decrease in spanwise and time averaged effectiveness can be observed both between the two rows of holes and downstream of the second row of holes. and in Figure 9. At $f=7 \mathrm{~Hz}$, the spanwise-averaged efficiency dropped $10 \%-18.5 \%$ compared with baseline condition after the second row of holes, while at $f=25 \mathrm{~Hz}$ the spanwise-averaged efficiency dropped as much as $16.7 \%-35.8 \%$ compared with baseline condition.

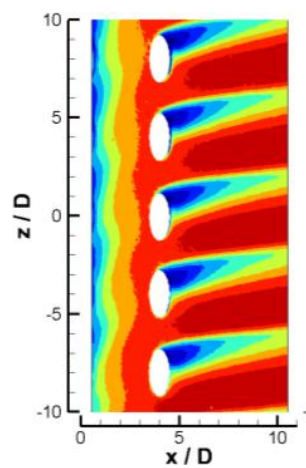

(a)

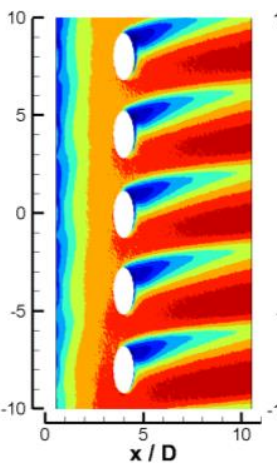

(b)

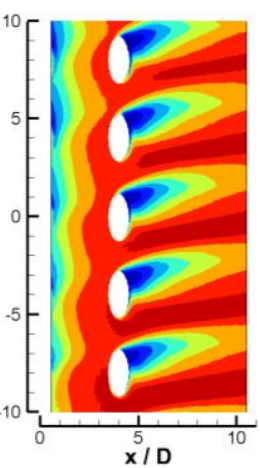

(c)

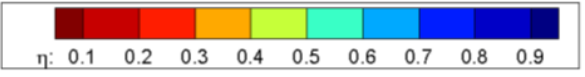

Figure 10. Time-averaged result at $M=1.0$

(a) $f=0 H z$, (b) $f=7 \mathrm{~Hz}$, (c) $f=25 \mathrm{~Hz}$

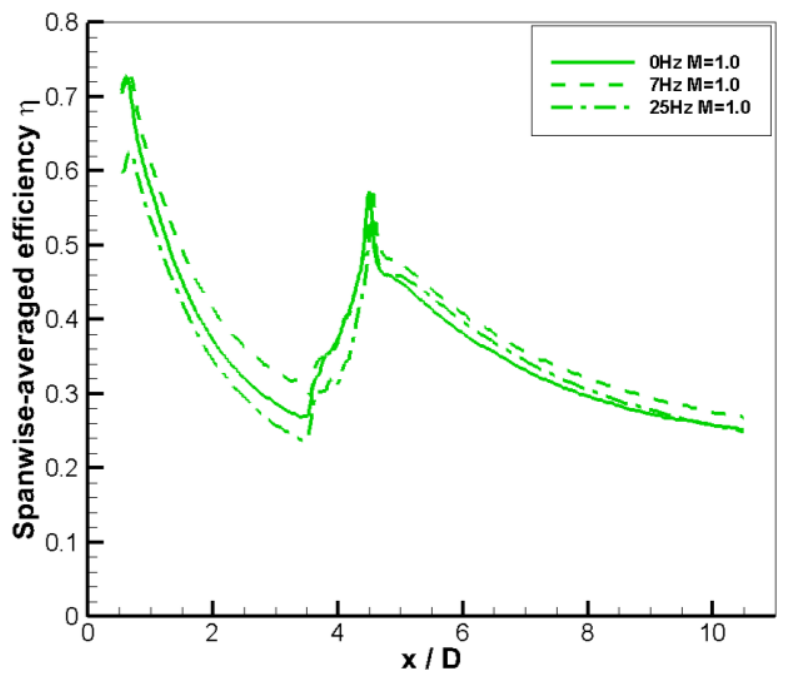

Figure 11. Spanwise \& time-averaged effectiveness profile at $\mathrm{M}=\mathbf{1 . 0}$

As can be observed from Figure 11, the time averaged effectiveness shows different features from lower blowing ratio. At $\mathrm{f}=7 \mathrm{~Hz}$, the overall film cooling effectiveness pattern is similar with, but slightly better than baseline condition, especially between the two rows of holes. At $\mathrm{f}=25 \mathrm{~Hz}$, the footage downstream the second row of holes is observed to stretch a shorter streamwise distance, but wider in spanwise. This could be caused by the oscillating mainstream flow forcing the coolant jet periodically sweep across the surface.

\subsubsection{Time-averaged effectiveness, $M=1.5$}




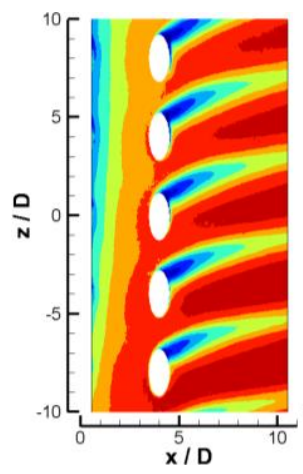

(a)

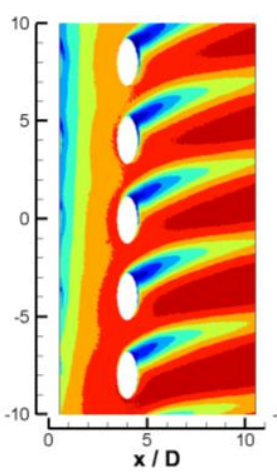

(b)

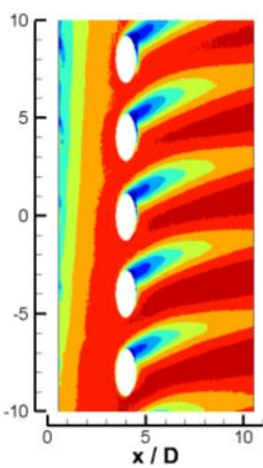

(c)

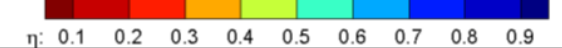

Figure 12. Time-averaged result at $M=1.0$

(a) $f=0 H z$, (b) $f=7 \mathrm{~Hz}$, (c) $f=25 \mathrm{~Hz}$

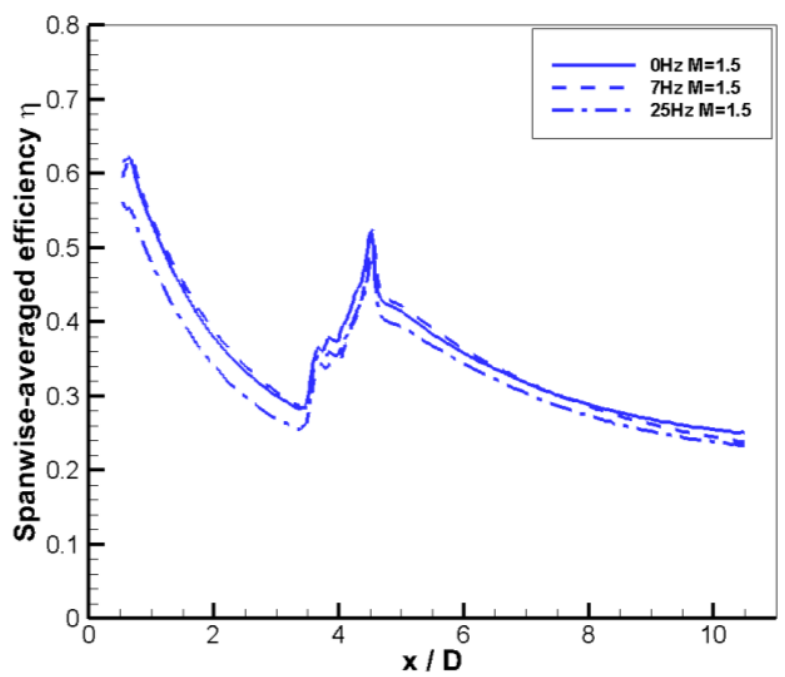

Figure 13. Spanwise \& time-averaged effectiveness profile at $M=1.5$

As can be shown from Figure 12 , at $\mathrm{f}=7 \mathrm{~Hz}$, there's no significant change of film cooling pattern compared with baseline condition given $\mathrm{M}=1.5$. While at $\mathrm{f}=25 \mathrm{~Hz}$, the film cooling effectiveness footage has decreased, this phenomenon can also be found out on spanwise averaged results in Figure 13. The film cooling effectiveness dropped about 5.5\%-6.8\% at $\mathrm{f}=25 \mathrm{~Hz}$ compared with baseline condition $(0 \mathrm{~Hz}, \mathrm{M}=1.5)$.

To summarize, the general patterns of time-averaged film cooling effectiveness for each blowing ratio is similar when the frequency varies. The time-averaged film cooling effectiveness is found to decrease significantly at lower blowing ratio $(\mathrm{M}=0.5$ in this case) when mainstream oscillation is in existence. However, at higher blowing ratio $(\mathrm{M}=1.0 \& 1.5)$, the influence of mainstream oscillation on time-averaged film cooling effectiveness is not very significant compared with that in the lower blowing ratio case.

\subsection{Phase-averaged film cooling effectiveness}

Since the coolant footage varies during every cycle of mainstream oscillation, it is of great importance to investigate the distribution of film cooling effectiveness with regard to the phase of mainstream oscillation.

$$
\tilde{\eta}=\frac{1}{N} \sum_{n=0}^{N} \eta(x, z, t+n \tau) \quad \mathrm{n}=1,2,3 \ldots \mathrm{N}
$$

Among Equation $3 \tau$ is the period of the mainstream oscillation, and $\mathrm{N}$ is the total number of mainstream oscillation cycles recorded when acquiring the instantaneous film cooling effectiveness information.

3.4.1 Phase-averaged effectiveness, $f=25 \mathrm{~Hz}, M=0.5$
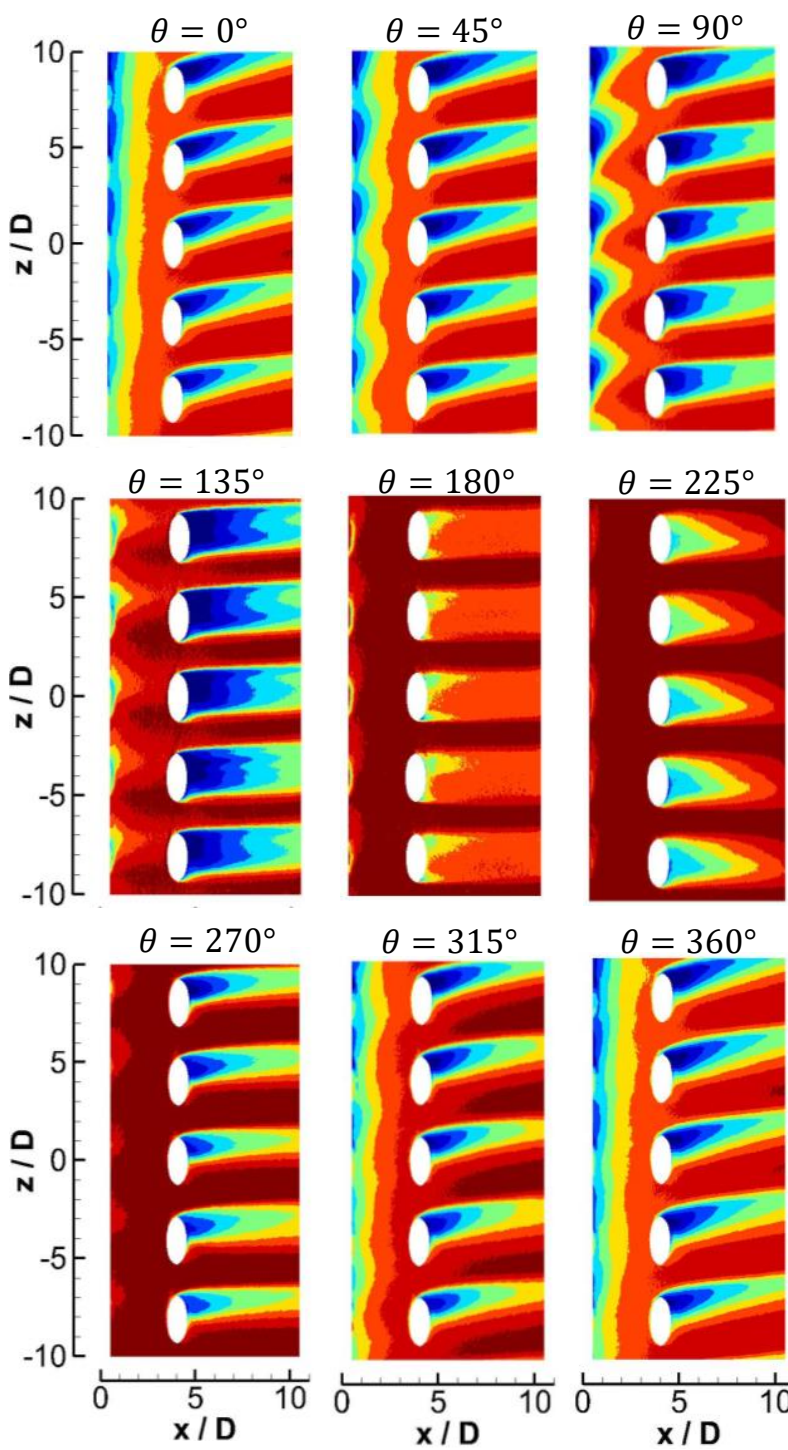

$\theta=315^{\circ}$
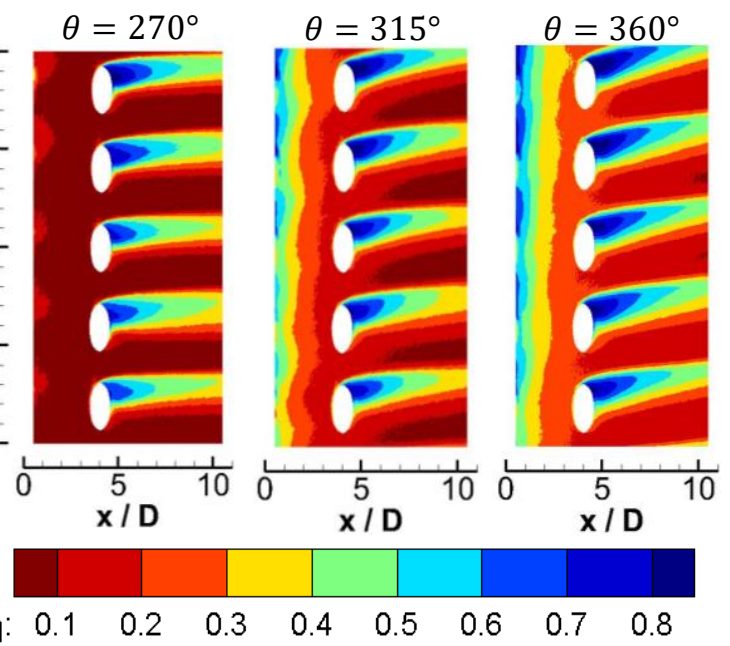

Figure 14. Phase-averaged effectiveness

\section{at $\mathrm{f}=25 \mathrm{~Hz} \mathrm{M}=0.5$}

Figure 14 depicts the phase-averaged adiabatic film cooling effectiveness. Note that the phase angle above represents the phase of the mainstream velocity measured by the hotwire anemometer $(\sin \theta)$. The oscillation of coolant film with mainstream is obvious. Starting from $\theta=0^{\circ}$, the coverage of coolant film gradually increases with $\theta$, until it reaches its maximum coverage at the phase angle $\theta=135^{\circ}$. The footage 
dramatically decreased at phase angle $\theta=180^{\circ}$ and then increase again with the increase of phase angle.

\subsubsection{Phase-averaged effectiveness, $f=25 \mathrm{~Hz}, M=1.0$}

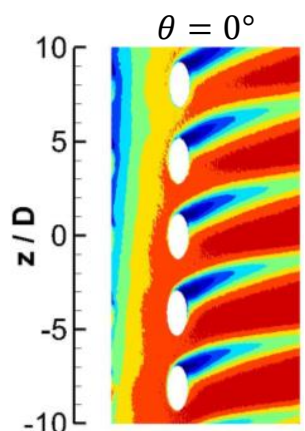

$\theta=135^{\circ}$
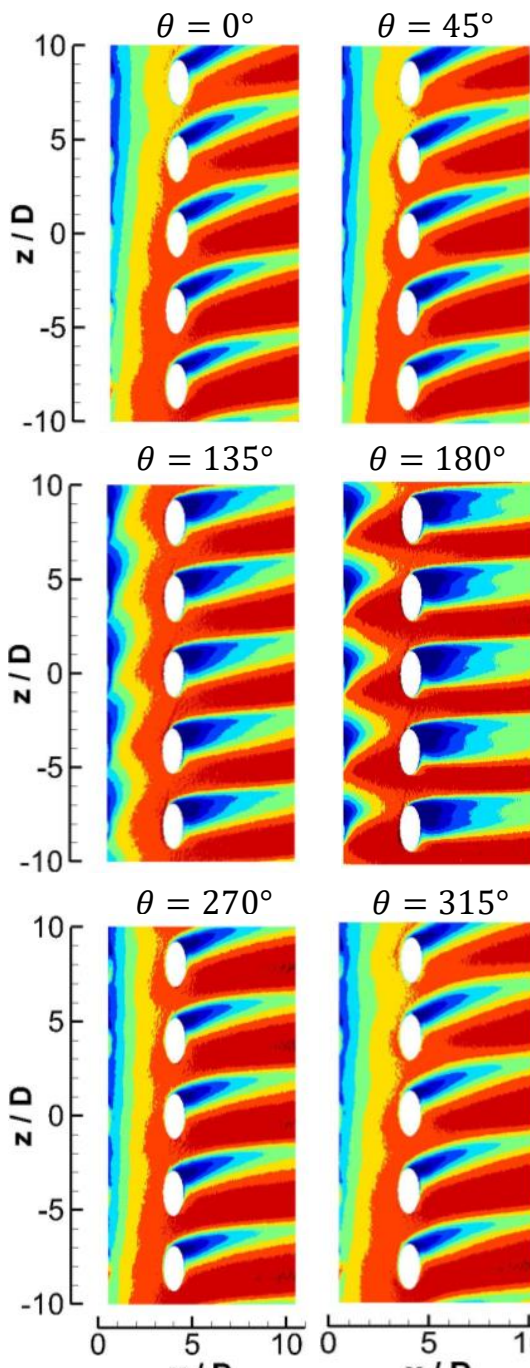

$\theta=180^{\circ}$
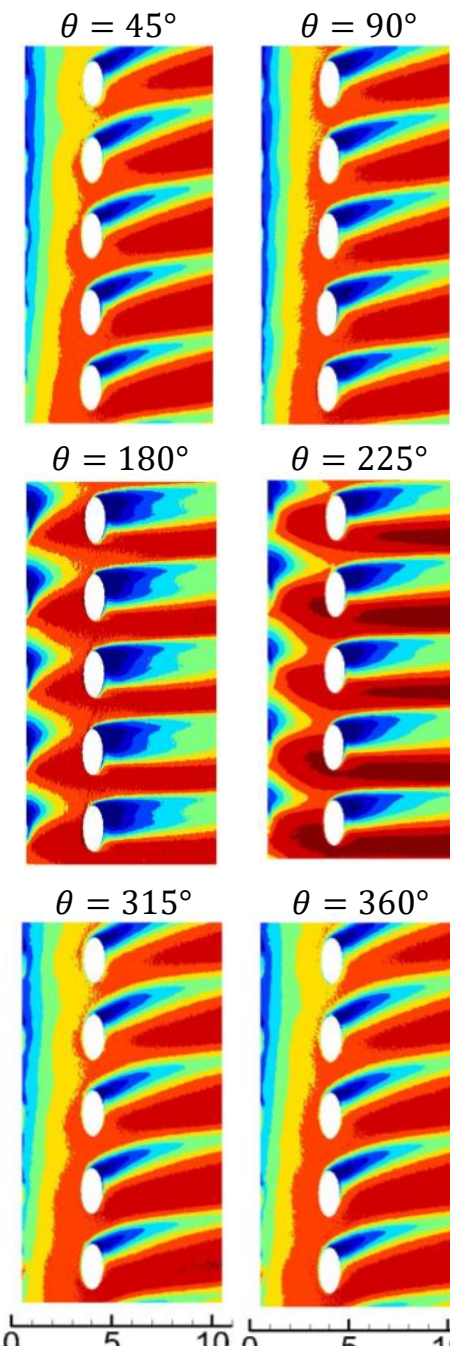

$\theta=225^{\circ}$

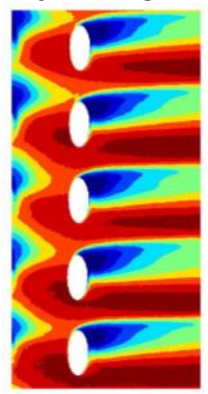

$\theta=360^{\circ}$
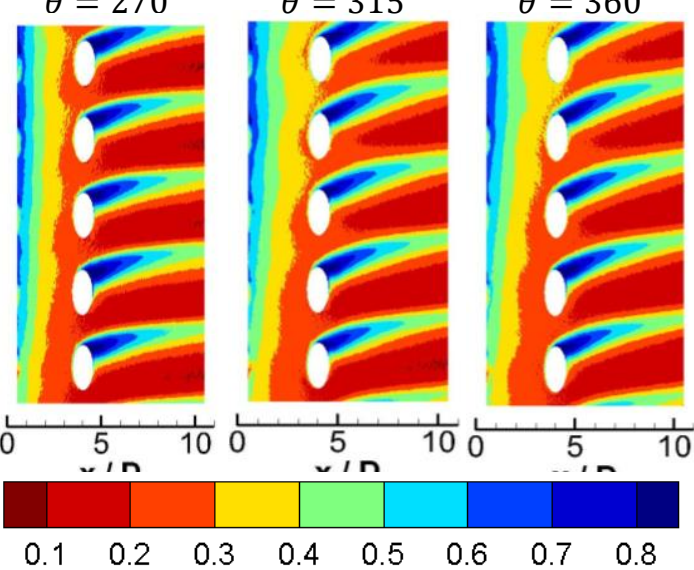

Figure 15. Phase-averaged effectiveness

\section{at $\mathrm{f}=25 \mathrm{~Hz} \mathrm{M}=1.0$}

The interaction between mainstream oscillation and coolant film footage is clearly shown in Figure 15. The coverage of coolant film increases monotonously with phase angle from $\theta=0^{\circ}$ to $\theta=180^{\circ}$ and decreases with the increase of phase angle from $\theta=180^{\circ}$ to $\theta=360^{\circ}$. This forms the cycle of the oscillation of coolant film footage. It is worth noticing that compared with lower blowing ratio $\mathrm{M}=0.5$, there's no sudden degradation of coolant film coverage. The reason could be the excessive coolant provided which can still provide sufficient coverage when the oscillation reaches its peak.

\subsubsection{Phase-averaged effectiveness, $f=25 \mathrm{~Hz}, M=1.5$}
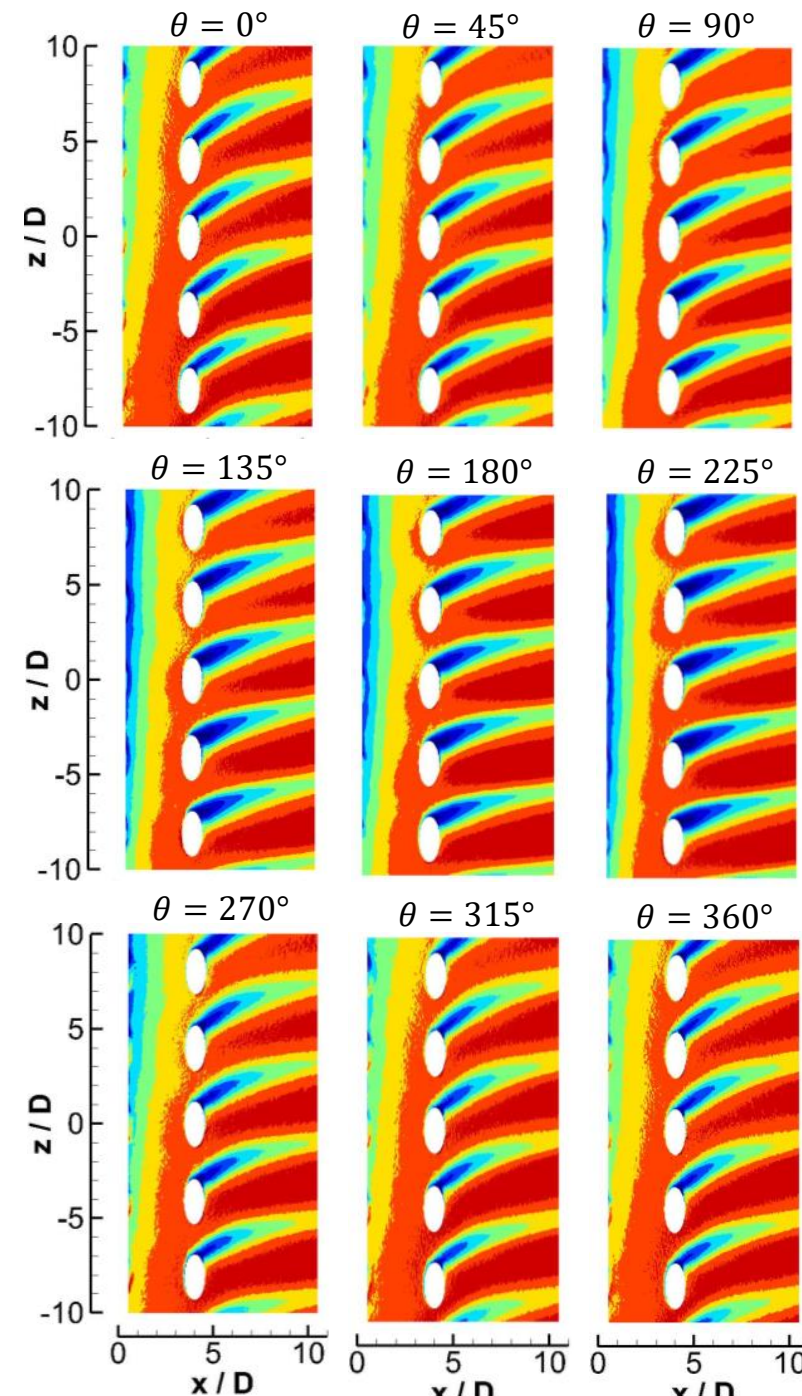

$\theta=315^{\circ}$

$\theta=360^{\circ}$
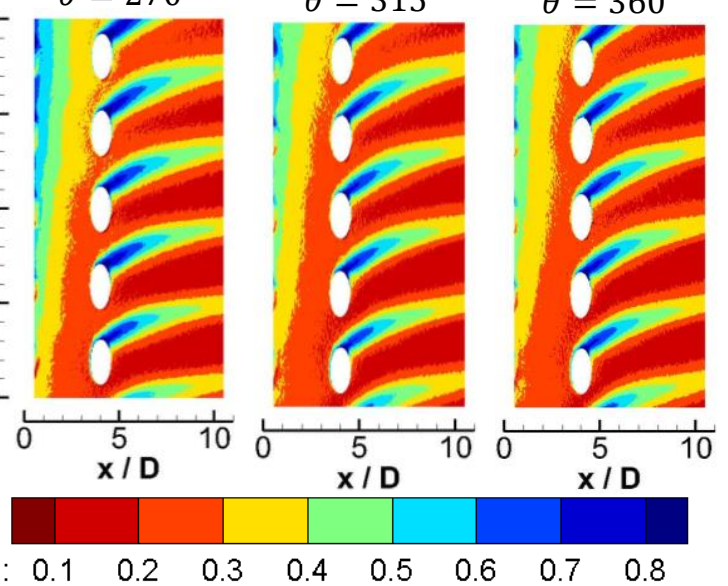

0.4

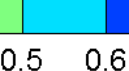

$0.7 \quad 0.8$

\section{Figure 16. Phase-averaged effectiveness}

\section{at $\mathrm{f}=25 \mathrm{~Hz} \quad \mathrm{M}=1.5$}

Compared with $\mathrm{M}=0.5$ and $\mathrm{M}=1.0$ case, in this case the phase-average film cooling efficiency pattern tend to be more insensitive to mainstream oscillation. This could result from the relatively low coolant Strouhal number. Due to the high blowing ratio, the coolant gas has higher speed, which makes it travel a given distance within a shorter period of time. This makes the coolant gas less exposed to mainstream oscillation, as a result causes the coolant film more robust.

\section{CONCLUSIONS}

Experiments have been conducted to investigate the influence of mainstream oscillation on spatio-temporal variation of leading-edge film cooling effectiveness. By combining Fast-response PSP with high speed camera, the instantaneous film cooling results are successfully obtained. Carbon Dioxide $\left(\mathrm{CO}_{2}\right)$ is discharged from the cooling holes 
from the leading-edge model to simulate heat transfer using mass transfer analogy. Blowing ratio varies between $M=0.5$, 1.0 and 1.5 . Steady mainstream flow $(0 \mathrm{~Hz})$ results are treated as baseline, details are investigated with frequency set at $7 \mathrm{~Hz}$ and $25 \mathrm{~Hz}$, which aims to produce similar mainstream oscillation amplitude. The results consist of time-averaged film cooling effectiveness distribution, time-averaged, spanwise-averaged film cooling effectiveness and phaseaveraged film cooling effectiveness distribution.

At steady mainstream condition, blowing ratio $\mathrm{M}=0.5$ shows better spanwise-averaged effectiveness downstream of the second row of holes than $M=1.0$ and $M=1.5$. While the latter two cases show better cooling efficiency between the first and second row of holes.

The time-averaged results show that mainstream oscillation significantly reduced the film-cooling footprint at lower blowing ratio. For $\mathrm{M}=0.5$, the spanwise-averaged cooling efficiency shows $10-18.5 \%$ reduction at $\mathrm{f}=7 \mathrm{~Hz}$, and $16.7-35.8 \%$ reduction compared with baseline condition at $\mathrm{f}=25 \mathrm{~Hz}$. At higher blowing ratio the change of cooling effectiveness with regard to mainstream oscillation is insignificant, indicating a more robust coolant coverage.

Phase-averaged results clearly pictured the interaction between mainstream oscillation and coolant gas film. Given the same mainstream velocity oscillation amplitude, at lower blowing ratio, which corresponds to higher coolant Strouhal number, the coolant film shows stronger oscillation; Higher blowing ratio, however, leads to weaker oscillation of the coolant footage. A sudden degradation of coolant film coverage is found at $\mathrm{f}=25 \mathrm{~Hz}, \mathrm{M}=0.5$, phase angle $\theta=180^{\circ}$, which needs further investigation.

\section{ACKNOWLEDGMENTS}

The authors gratefully acknowledge the financial support for this study from the Natural Science Foundation of China (11725209, 51806138) and the Shanghai Sailing Program (18YF1411300).

\section{Nomenclature}

$\begin{array}{ll}A & \text { oscillating amplitude } \\ d & \text { diameter of coolant hole } \\ D & \text { diameter of leading edge } \\ D R & \text { coolant-to-mainstream density ratio } \\ f & \text { oscillating frequency } \\ L & \text { entry length of the coolant hole } \\ L e & \text { Lewis number } \\ M & \text { blowing ratio } \\ P & \text { pitch of coolant holes } \\ S t_{\mathrm{c}} & \text { coolant Strouhal number } S t_{\mathrm{c}}=2 \pi f L / U_{\mathrm{c}} \\ T_{\mathrm{aw}} & \text { adiabatic wall temperature } \\ T_{\mathrm{c}} & \text { coolant stream temperature } \\ T_{\infty} & \text { temperature of the mainstream flow } \\ U_{\mathrm{c}} & \text { coolant stream mean velocity } \\ U_{\infty} & \text { bulk flow velocity }\end{array}$

$$
\begin{array}{ll}
\text { Greek symbols } \\
\alpha & \text { thermal diffusion coefficient } \\
\theta & \text { phase angle }
\end{array}
$$

\section{Abbreviations}

Fast-PSP fast-response pressure-sensitive paint

MCU micro control unit

TET turbine entry temperature

\section{References}

[1] Baek, S. and Yavuzkurt, S. (2016). Effects of Oscillations in the Main Flow due to Thermo Acoustic Fields in a Gas Turbine Combustor on Film Cooling. ASME Turbo Expo, 2016, GT2016-56402. doi:10.1115/GT2017-63398.

[2] Cai, T., Peng, D., Yavuzkurt, S., Liu, Y., 2018, "Unsteady 2-D Film-Cooling Effectiveness Behind A Single Row of Holes at Different Blowing Ratios: Measurements Using Fast-Response PressureSensitive Paint," Int. J. Heat Mass Transf., vol. 120, pp. 1325-1340.

[3] Khojasteh, A., Wang, S., Peng, D., Yavuzkurt, S., Liu, Y. (2017), "Structure Analysis of Adiabatic Film Cooling Effectiveness in The Near Field of a Single Inclined Jet: Measurement Using Fast-Response Pressure-Sensitive Paint," Int. J. Heat Mass Transf., vol. 110, pp. 629-642.

[4] Li, X., Sun, B., You, H., Wang, L. (2015). Evolution of Rolls-Royce Air-cooled Turbine Blades and Feature Analysis. Procedia Engineering, vol 99, pp. 1482-1491.

[5] Ligrani, P.M., Gong, R., Cuthrell, J.M., Lee J.S., (1996) Bulk flow pulsations and film cooling-I. Injectant behavior, Int. J. Heat Mass Transf. vol. 39, pp. 2271-2282.

[6] Ligrani, P.M., Gong, R., Cuthrell, J.M., Lee J.S., (1996) Bulk flow pulsations and film cooling-II. Flow structure and film effectiveness, Int. J. Heat Mass Transf. vol. 39 pp. 2283-2292.

[7] Zhou, W., Qenawy, M., Liu, Y., Wen, X., Peng, D., 2019, Influence of Mainstream Flow Oscillations on Spatio-Temporal Variation of Adiabatic Film Cooling Effectiveness, Int. J. Heat Mass Transf., vol. 129, pp. 569-579. 